\title{
Minimally Invasive Aesthetic Treatment of the Face and Neck Using Combinations of a PCL-Based Collagen Stimulator, PLLA/PLGA Suspension Sutures, and Cross-Linked Hyaluronic Acid
}

This article was published in the following Dove Press journal:

Clinical, Cosmetic and Investigational Dermatology

\section{Francisco de Melo' Alieksiéi Carrijo ${ }^{2}$ Kyungkook Hong ${ }^{3}$ Bruno Trumbic (iD) 4 Franco Vercesi $\mathbb{1}^{5}$ Heidi A Waldorf ${ }^{6}$ Sabine Zenker $^{7}$}

'Aesthetics International, Dubai, United Arab Emirates; ${ }^{2}$ Clínica Carrijo, São Paulo, Brazil; ${ }^{3}$ Hus-hu Dermatology Clinic, Seoul, South Korea; ${ }^{4}$ Cap Evidence, Paris, France; ${ }^{5}$ Aesthetic Surgery and Laser, Milan, Italy; ${ }^{6}$ Waldorf Dermatology Aesthetics, Nanuet, NY, USA; ${ }^{7}$ Dr Zenker Dermatology, Munich, Germany
Correspondence: Francisco de Melo Tel +97I 561753929

Email franciscofmelo@gmail.com
Background: Combinations of minimally invasive procedures (MIPs) are often used in aesthetic treatments and are increasingly considered as the new standard of care. Three agents with specific properties are available in this perspective: a polycaprolactone (PCL)based collagen stimulator, a poly-L-lactic acid (PLLA)- and a poly-glycolic acid (PLGA)based resorbable suspension suture with a 3D-cone technology, and a cross-linked hyaluronic acid (HA).

Objective: To develop the first practice guidelines on rejuvenation treatment of the face and the neck using combinations of these agents, whether associated or not with other widely used MIPs such as botulinum neurotoxins or energy-based devices.

Methods: A multi-disciplinary, multi-national board of plastic surgeons and dermatologists convened to develop guidelines using a predefined consensus method. The consensus was defined as $\geq 83 \%$ agreement rate between participants.

Results: Practice guidelines and algorithms, describing optimal procedure sequence and spacing, are proposed for the treatment of upper-, mid-, lower-face and neck, combining the PCL collagen stimulator, the PLLA/PLGA suspension sutures, and the cross-linked HA, whether associated or not with other MIPs.

Conclusion: These new guidelines provide general support to optimal management strategies. Individual treatment plans should be adapted according to the physician's individual competence and the patient's preferences.

Keywords: botulinum toxins, combined modality therapy, dermal fillers, energy-based device, practice guideline, rejuvenation

\section{Introduction}

Since the appearance of skin and face are considered important factors of wellbeing and health, the number of aesthetic procedures performed worldwide is continuously increasing. ${ }^{1,2}$ For instance, according to the American Society of Plastic Surgeons, 17.7 million surgical and minimally invasive cosmetic procedures were performed in the United States (US) in $2018 .^{3}$

In this context, the use of minimally invasive procedures (MIPs) increased strongly by $+228 \%$ growth rate between years 2018 and 2000 in the US, ${ }^{3}$ and MIPs represent now nearly $90 \%$ of aesthetic interventions. ${ }^{4}$ They aim to attain optimal results with minimal invasiveness, faster recovery, reduced scarring, limited 
stress, and better patient satisfaction. ${ }^{5}$ They include a wide range of injectable agents, devices, and techniques, each being performed in precise indications. The most often used injectable agents are the Clostridium botulinumderived botulinum neurotoxins (BoNTx), which induce a temporary relaxation of muscles, ${ }^{6}$ and hyaluronic acidbased (HA) biodegradable soft-tissue fillers. ${ }^{7,8}$ Other biodegradable fillers, based on calcium hydroxylapatite (CaHA), polycaprolactone (PCL) or poly-L-lactic acid (PLLA), possess additional bio-stimulatory properties. ${ }^{9-11}$ The term "energy-based devices" (EBDs) encompasses different purposes and devices, ie, tightening (micro modelling) vs resurfacing techniques. Commonly used EBDs in face and neck rejuvenation are radio frequency (RF) for skin tightening and collagen contraction, skin resurfacing lasers, and high-intensity focused ultrasound (HIFU) for wrinkle reduction and skin tightening. ${ }^{6,12-15}$ While mechanical liposuction and chemical lipolysis are used for fat reduction, intense pulsed light (IPL) is used for improving skin colour and texture.

\section{Combination Treatments: The New Standard of Care}

MIPs are increasingly utilised in combination protocols to improve outcomes. ${ }^{16}$ In 2014, nearly half of all aesthetic patients in the US who requested MIPs received multiple procedures. ${ }^{4}$ Indeed, combination treatments offer an optimal response to the multifactorial process of facial ageing, which involves structural changes in all anatomical layers (bone, muscles, ligaments, adipose tissue, and skin) and dynamic interactions among these tissues. ${ }^{2,17,18}$ Consequently, the modern concept of natural and harmonious rejuvenation is based on a comprehensive, threedimensional, multi-layered approach, combining multiple agents and techniques to attain multiple goals such as relaxation, volumisation, volume repositioning, reshaping, resurfacing, or tightening, depending on specific patient needs. $^{6,17,19}$

Diverse multimodal approaches have been assessed for face and neck rejuvenation in clinical studies (Table 1). The studies have generally concluded that combination treatments display additive or even synergistic effects, leading to better and longer-lasting results compared to single agent- or single technique-based protocols, with no clinical evidence of increased adverse events (AEs) rate or severity. ${ }^{6,16,20-22}$ Therefore, combined treatments are now considered the new standard of care. ${ }^{18}$
Table I Published Multimodal Approaches Proposed for Face or Neck Rejuvenation

\begin{tabular}{|c|c|}
\hline Face & Neck ( \pm Decolletage) \\
\hline \multicolumn{2}{|l|}{ RCTs (n Patients) } \\
\hline \multicolumn{2}{|l|}{$\begin{array}{l}\text { HA filler + RF vs HA filler }(n=10)^{57} \\
\text { BoNTx + HA filler vs BoNTx }(n= \\
20)^{58} \\
\text { BoNTx + HA filler vs BoNTx + HA } \\
\text { filler + cosmetic treatment }(n=20)^{59} \\
\text { BoNTx + HA filler vs BoNTx vs HA } \\
\text { filler }(n=90)^{60}\end{array}$} \\
\hline \multicolumn{2}{|c|}{ Non-Randomized Studies and Case Reports (n Participants) } \\
\hline $\mathrm{HA}$ filler $+\mathrm{RF}+(\mathrm{n}=1)^{61}$ & $\begin{array}{l}\text { BoNTx + HA filler + MFU- } \\
V\left(\text { or CaHA) }(n=10)^{56}\right.\end{array}$ \\
\hline $\begin{array}{l}\text { BoNTx + HA filler + laser resurfacing } \\
(n=1)^{62}\end{array}$ & $\begin{array}{l}\text { BoNTx + HA filler + IFU (n } \\
=(2)^{63}\end{array}$ \\
\hline $\begin{array}{l}\text { BoNTx + CaHA + HA filler }+ \\
\text { injectable PLLA }(n=2)^{20}\end{array}$ & $\mathrm{CaHA}+\mathrm{MFU}-\mathrm{V}(\mathrm{n}=47)^{64}$ \\
\hline $\begin{array}{l}\text { BoNTx }+ \text { CaHA + HA filler + MFU-V } \\
(n=10 I)^{65} \\
\text { BoNTx + HA filler }(n=60)^{66} \\
\text { Bimatoprost }{ }^{\mathrm{a}}+\text { BoNTx + HA filler }(n \\
=(16)^{55}\end{array}$ & $\begin{array}{l}\text { BoNTx + CaHA + HA filler } \\
+ \text { MFU-V }(n=101)^{65}\end{array}$ \\
\hline \multicolumn{2}{|l|}{ Reviews } \\
\hline $\begin{array}{l}\text { BoNTx }+ \text { HA filler }+ \text { various EBDs } \\
\text { (laser, IPL, MFUS, FMR) } \\
\text { BoNTx or HA fillers + IPL + lasers } \\
\text { (ablative and non-ablative) }+\mathrm{RF}^{67}\end{array}$ & Various techniques ${ }^{\mathrm{b}} 52$ \\
\hline
\end{tabular}

Notes: ${ }^{\mathrm{a} B i m a t o p r o s t} 0.3 \%$ ophthalmic solution; ${ }^{\mathrm{b}} \mathrm{ATX}-\mathrm{I0I}$, ablative and non-ablative fractional lasers, BoNTx, cryolipolysis, HA fillers, IPL, laser lipolysis, liposuction, MFU-V, monopolar RF.

Abbreviations: BoNTx, botulinum neurotoxin; CaHA, calcium hydroxyapatite; FMR, fractional microneedle radiofrequency; HA, hyaluronic acid; IFU, intensity focused ultrasound; IPL, intense pulsed light; MFUS, micro-focused ultrasound; MFU-V, micro-focused ultrasound with visualization; PLLA, poly-L-lactic acid; RCT, randomized controlled trial; RF, radiofrequency; US, ultrasound.

\section{PCL Collagen Stimulator, PLLA/PLGA Suspension Sutures, Cross-Linked HA}

Three distinct agents have been proposed by a single company (Sinclair Pharmaceuticals, London, UK) for minimally invasive rejuvenation treatments: a biodegradable collagen stimulator (Ellansé ${ }^{\circledR}$ ), a resorbable suspension suture with a 3D-cone technology (Silhouette Soft ${ }^{\circledR}$ ), and a cross-linked HA (Perfectha ${ }^{\circledR}$ ).

The collagen stimulator is composed of bioresorbable PCL microspheres suspended in an aqueous carboxymethylcellulose gel carrier. In addition to their soft-tissue filler effect, the microspheres stimulate the production of new collagen, ${ }^{11,23}$ resulting in volume restoring, face 
Table 2 Sinclair Pharmaceuticals Products for Minimally Invasive Rejuvenation

\begin{tabular}{|c|c|c|c|}
\hline & PCL Collagen Stimulator ${ }^{a}$ & $\begin{array}{l}\text { PLLA/PLGA Suspension } \\
\text { Suture }^{b}\end{array}$ & Cross-Linked HA ${ }^{c}$ \\
\hline Concept & $\begin{array}{l}\text { Dermal filler stimulating collagen } \\
\text { production }\end{array}$ & 3D cone-based suspension suture & $\begin{array}{l}\text { Cross-linked resorbable high molecular weight } \\
\text { HA gel }\end{array}$ \\
\hline Indications & $\begin{array}{l}\text { Volume restoration } \\
\text { Facial reshaping } \\
\text { Skin quality improvement }\end{array}$ & $\begin{array}{l}\text { Facial and neck contour reshaping } \\
\text { Tissue repositioning } \\
\text { Collagen stimulation }\end{array}$ & $\begin{array}{l}\text { Wrinkle correction } \\
\text { Volume restoration } \\
\text { Facial contouring }\end{array}$ \\
\hline $\begin{array}{l}\text { Product } \\
\text { range }\end{array}$ & $\begin{array}{l}3 \text { Products } \\
\text { - } \geq 18 \text { Months } \\
\text { - } 24 \text { Months } \\
\text { - } 36 \text { Months } \\
\text { Duration of effect }\end{array}$ & $\begin{array}{l}3 \text { Products } \\
\text { - } 8 \text { Cones } \\
\text { - } 12 \text { Cones } \\
\text { - } 16 \text { Cones }\end{array}$ & $\begin{array}{l}5 \text { Products } \\
\text { - BDDE cross-linked HA gels }(20 \mathrm{mg} / \mathrm{mL}) \\
\text { - Variable particle sizes }\end{array}$ \\
\hline
\end{tabular}

Notes: ${ }^{a}$ Ellansé ${ }^{\circledR} ;{ }^{b}$ Silhouette Soft ${ }^{\circledR} ;{ }^{c}$ Perfectha ${ }^{\circledR} ;{ }^{d}$ Expected longevity in vivo based on extrapolation of clinical data from S and M versions and accepted PCL degradation behavior.

Abbreviations: BDDE, butanediol diglycidyl ether; HA, hyaluronic acid; PCL, polycaprolactone; PLLA/PLGA, poly-L-lactic acid/poly-glycolic acid.

reshaping, and skin quality improvement. Three versions are available (Ellansé- $\mathrm{S}^{\circledR},-\mathrm{M}^{\circledR},-\mathrm{L}^{\circledR}$ ), providing the duration of effect from at least 18 months up to 3 years (Table 2), ${ }^{24,25}$ as the degradation time of the PCL microspheres depends on the initial polymer chain length. ${ }^{26-28}$ Clinical studies, including prospective randomized controlled trials (RCTs), have shown product safety and efficacy in the treatment of nasolabial folds, ${ }^{29,30}$ forehead augmentation, ${ }^{31}$ hand rejuvenation, ${ }^{32}$ and complete facial rejuvenation. ${ }^{33}$ Consensus guidelines stated that this PCL collagen stimulator offers noteworthy advantages over PLLA-based fillers, as the results are immediately visible, and over HA- and CaHA-based fillers, due to better stability and duration of the results. ${ }^{34}$ A worldwide post market survey (2012-2019) found a $0.0562 \%$ AEs rate, confirming excellent safety in daily practice. ${ }^{35}$

The suspension sutures are made of PLLA biodegradable monofilaments that support resorbable 3D cones made of a copolymer of PLLA and poly-glycolic acid (PLGA). These unique features lead to a dual effect: an immediate repositioning of the sagging tissue and, thanks to the collagen stimulation, a gradual and sustained tissue regeneration. The sutures are utilised in the treatment of mild to moderate skin sagging on the mid-face, lower face, full face, neck, and in eyebrow repositioning. Three product references are available ( 8 cones, 12 cones, and 16 cones) to address different areas and degrees of skin laxity. Clinical studies have shown the efficacy of these threads as well as their long-lasting effect and safety, with the observed AEs being mild to moderate and easily manageable. ${ }^{36-38}$ A post market survey (2012-2019) found a very limited $0.0231 \%$ overall AEs rate. ${ }^{39}$ A recent US-based expert consensus concluded that the treatment with absorbable facial suspension sutures, when performed properly, is associated with minor and infrequent AEs, offering a beneficial clinical alternative to traditional facial rejuvenation techniques. ${ }^{40}$

The third product range includes resorbable high molecular weight and high purity HA gels of non-animal origin which are cross-linked with butanediol diglycidyl ether. Five different versions are available. All the products of the range have the same HA concentration $(20 \mathrm{mg} / \mathrm{mL})$, but their particle sizes and rheological properties vary: the bigger the particles, the greater the volumizing effect and the longerlasting the results. Thus, each gel is different and designed to best meet specific needs, depending on the area to be treated, the volume needed, and the depth of injection required. As a consequence, these agents are utilised in a wide range of rejuvenation treatments: from superficial or deep lines filling to volume creation and contour shaping. ${ }^{41,42}$ Clinical studies have shown their efficacy, lasting for six to 18 months, as well as a high level of patient and physician satisfaction. ${ }^{43-46}$ Devoid of inflammatory effects, ${ }^{47}$ these cross-linked HA gels are safe in daily clinical use as evidenced by a post market survey (2012-2019) that found a $0.0239 \%$ AEs rate out of 2.8 million syringes sold worldwide. ${ }^{48}$

In daily practice, the PCL collagen stimulator, the PLLA/ PLGA suspension sutures, and the cross-linked HA are most often combined in multimodal rejuvenation protocols. As no specific recommendations existed to guide this frequent practice, the objective of the present work was to provide physicians with guidelines on the optimal use of these agents in combination in face and neck rejuvenation treatments. 


\section{Methods}

The guidelines were developed by a multi-disciplinary, multi-national board of plastic surgeons and dermatologists representing a worldwide perspective. As an initial step, each participant was asked to independently indicate personal preferences concerning the best-combined rejuvenation treatment of predefined target areas (neck, lower face, mid-face, and upper face) using a common standardized questionnaire. Participants were also asked to analyse frequent aesthetic problems separately within each area (eg, for lower face: loss of jawline contour, loss of submental cervical angle, and so on) in patients with mild or moderate to severe signs of aging. Individual preferences were compiled in anonymised summary tables, which were presented for discussion at a consensus meeting. All options were submitted to plenary votes to identify formal consensual statements according to the following criteria:

1. Agreement of six out of six experts: strong consensus,

2. Agreement of five out of six experts $(83 \%$ agreement): consensus,

3. Agreement of $\leq$ four/six experts: absence of consensus.

\section{Results and Recommendations}

The board commented on the initially proposed analytical approach, objecting that the adjectives "mild", "moderate", and "severe" are vague and subjective: a patient may well be sorted in different categories by different physicians. Thus, this approach cannot be used unless based on a validated and widely accepted (visual) scale. Moreover, differences in patient management according to severity are often only a matter of the number of sessions and product amounts, not different strategies. The focus on individual aesthetic unit problems within the same face area appeared superfluous and irrelevant: in daily practice, most patients are treated by combination protocols for more than one mutually correlated aesthetical problems within the same area.

However, a series of key orientations to categorize the usual problems and manage combination treatments were consensually agreed.

\section{Guidelines on Common Key-Principles}

It is not advisable to perform multiple procedures on the same area during the same session because scant data are available on possible interactions, making it difficult to accurately incriminate the responsible agent/procedure in case of an emergent AE. However, the board members acknowledged that they do not always follow this rule, assuming thereby increased personal responsibility and that no complications may arise from combining different treatment modalities in different anatomical areas during the same session.

As a rule, the rejuvenation protocol should successively aim for two main objectives: volume adjustment (reduction, replacement/augmentation or creation) in the first place, tissue reposition afterwards. A frequently needed optional final step aims at improving the overall result performing "touch up" and skin quality improvement procedures. Regarding volume replacement, the board favours the PCL collagen stimulator, as it offers an additional long-term rejuvenating effect by stimulating neocollagenesis, but HA fillers, as per the treating physician preference, can also be used.

Volume (fat) reduction can be performed by any physician's preferred usual technique (laser-assisted lipolysis, chemical lipolysis solution, liposuction, HIFU). Most board members recommend performing fat-reduction before PLLA/PLGA sutures insertion (respecting an interval of six to eight weeks after injection lipolysis, and a 12-week interval after liposuction or cryolipolysis); one participant prefers applying injection lipolysis two weeks after sutures insertion.

The PLLA/PLGA suspension sutures should be placed according to the currently recommended straight patterns, strictly avoiding the "U" and the angle ("L") patterns. The number of sutures implanted in every target area should be sufficient to induce optimal effect and patient satisfaction.

BoNTx injections are always recommended for eyebrows and neck rejuvenation, where they should be performed two weeks before the PLLA/PLGA sutures insertion, since complete muscular relaxation allows better cones encapsulation and a more stable effect (see the "blanket statement" in Table 3). Their use is optional in other areas where they are often injected before or during the same session as volume replacement.

The cross-linked HA fillers or the PCL collagen stimulator may also be injected as an elective last step, designed to improve the final result, thanks to a "touch up" effect, ie, fine-line/wrinkle correction, skin quality improvement and beautification (eg, lip enhancement/augmentation, additional volume augmentation, and so on). 
Table 3 Focus on Important Treatment Spacing Principles

Combined Use of EBDs and PLLA/PLGA Suspension Sutures
- EBD tightening techniques should be used 6-8 weeks before (pre-
ferably) or 8-12 weeks after the PLLA/PLGA sutures insertion.
- Resurfacing techniques should be performed 2-4 weeks before or
after (preferably) the PLLA/PLGA suspension sutures insertion.
Combined Use of BoNTx and PLLA/PLGA Suspension Sutures
- BoNTx injection should be performed 2 weeks before PLLA/
PLGA sutures insertion.
Optional Touch Up Treatment
- Should be injected 4-6 weeks after initial volume replacement/
augmentation when using the PCL collagen stimulator, or 2 weeks
after initial filler treatment when using the cross-linked HA.

Abbreviations: BoNTx, botulinum neurotoxin; EBD, energy-based device; HA, hyaluronic acid; PLLA/PLGA, poly-L-lactic acid/poly-glycolic acid.

\section{EBD Use}

Some EBD tightening techniques (eg, RF, US) may interfere with the fillers and the PLLA/PLGA sutures and impair the subsequent collagen production: It is thus recommended to perform them on separate sessions. They should preferably be performed before (6-8 weeks) the insertion of the PLLA/PLGA sutures: The key reason is that this period is needed to start collagen remodeling, resulting in better support for PLGA cones of the suspension sutures. If EBD tightening techniques are performed after suture insertion or filler injection, the interval should be longer (eight-12 weeks) to avoid the risk of suture breakage or filler meltdown.

When applied, EBD resurfacing techniques should preferably follow the PLLA/PLGA suspension sutures insertion (after a two-four-week interval). If resurfacing is performed before, the skin should be properly re-epithelized (healed) and made free of any resurfacing-associated complication or AEs (bacterial or viral infection, delayed healing areas) before suture insertion.

EBD techniques may be used at any of the above-cited locations in addition to other more area-specific treatments.

\section{Algorithms According to Treatment Areas}

Area-specific treatment algorithms were developed according to the key-principles described above and accounting for the usual area-specific rejuvenation priorities. To keep this report adequately concise, the proposed treatment sequences and spacings are specified in relevant figures, while the text highlights only some conceivable alternatives or noticeable comments.

\section{Upper Face}

The overall upper-face rejuvenation procedure (sequence and spacing) was agreed with a strong consensus level. It starts with systematic BoNTx injections, associated with volume replacement. The sequence then differs depending on whether further tissue reposition (eyebrows elevation) is based on either cross-linked HA or PCL collagen stimulator injections (Figure 1A) or on 8-cone PLLA/PLGA sutures insertion (Figure 1B). The final touch-up/refinement session is optional.

\section{Mid-Face}

Mid-face rejuvenation treatment starts with volume replacement, followed by tissue reposition (Figure 2); agreement level: strong consensus. The third "touch up" step is optional and should not be performed before the results of the previous steps are stabilized.

\section{Lower Face}

The overall lower-face rejuvenation procedure, starting with volume adjustment (reduction or replacement/augmentation) is described in Figure 3. A minor discrepancy existed between board members regarding the preferred sequence of injection lipolysis and the PLLA/PLGA sutures insertion: starting with injection lipolysis was the consensually adopted choice, but one participant preferred the reverse sequence; (overall agreement level: consensus). The BoNTx-based muscular relaxation ("Nefertiti lift"49,50) is optional and, when needed, should be separated by a two-week interval with the next step (tissue reposition, suture insertion). The last (fourth) "touch up" step is also optional.

\section{Neck}

The two- to four-step neck rejuvenation treatment may start with either an optional volume reduction, an optional EBD tightening or a systematic BoNTx-based platysma relaxation (Figure 4); overall agreement level: consensus. When performed, the EBD tightening should be separated by a long enough interval with the PLLA/PLGA sutures insertion (tissue reposition). Finally, an optional fifth step (dermal filler injections according to its instructions for use, two weeks after sutures insertion) may be needed to perfect the results.

\section{Discussion}

We propose here the first recommendations on the multimodal rejuvenation treatment of the face and neck involving three specific agents, ie, the PCL collagen 
A

\section{A. RELAXATION ORBICULARIS OCULI \\ (systematic)}

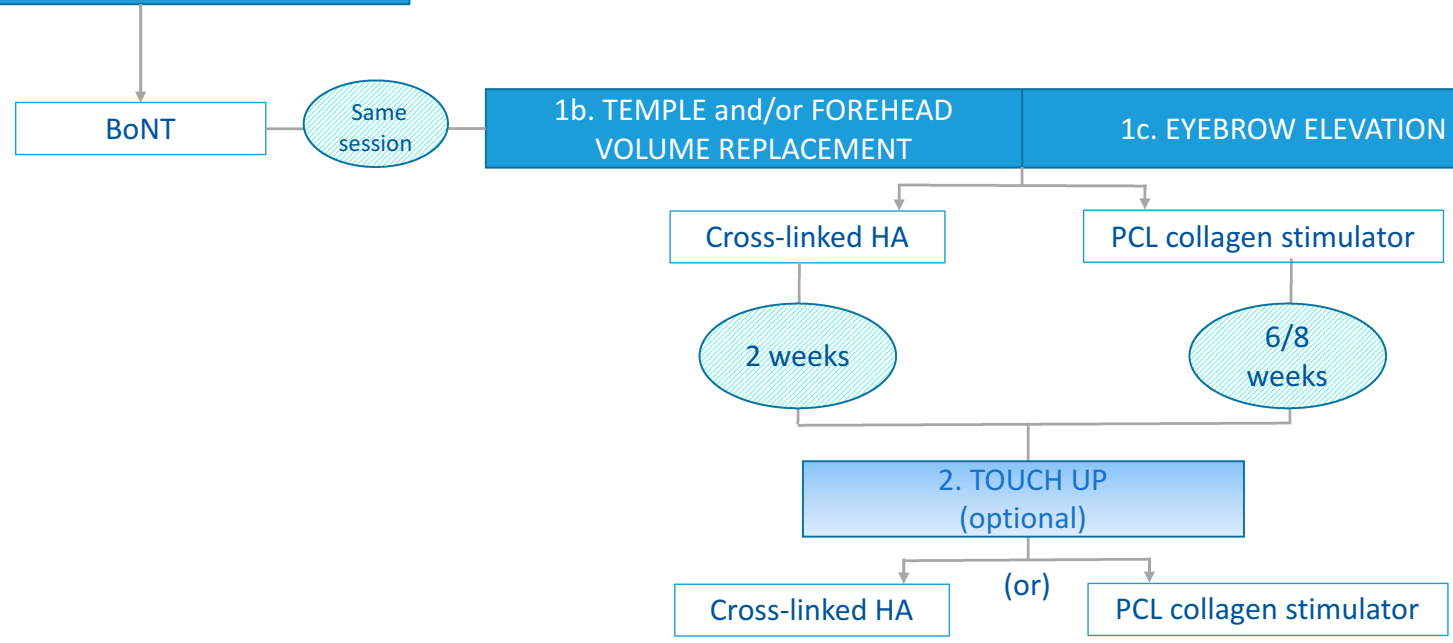

B
1a. RELAXATION ORBICULARIS OCULI
(systematic)
1b. TEMPLE and/or FOREHEAD
VOLUME REPLACEMENT

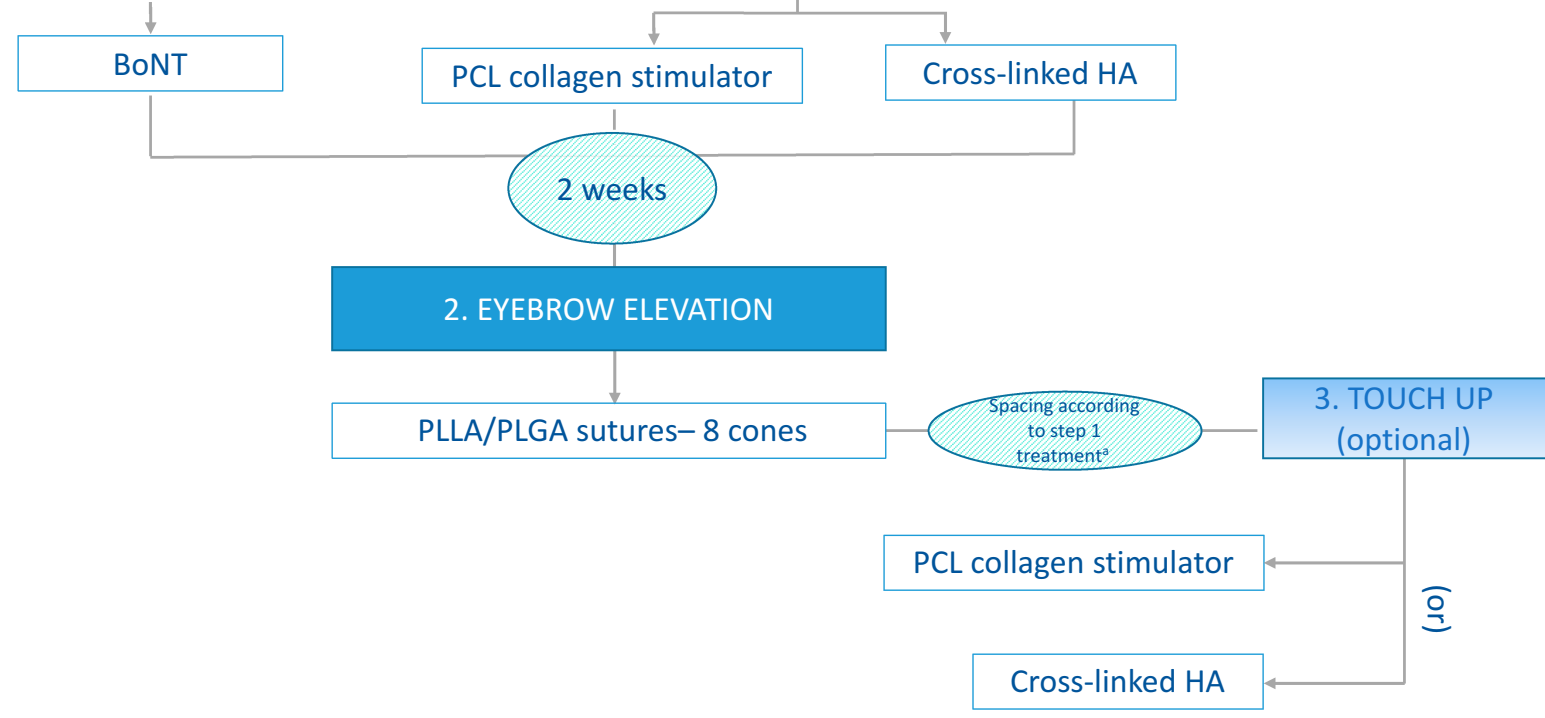

Figure I (A) Algorithm for upper-face rejuvenation when using cross-linked HA or PCL collagen stimulator injections for eyebrow elevation. (B) Algorithm for upper-face rejuvenation when using PLLA/PLGA sutures for eyebrow elevation.

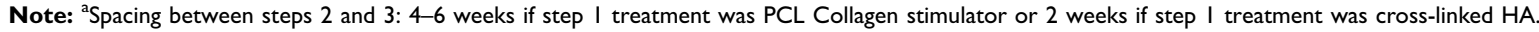

Abbreviations: BoNT, botulinum neurotoxin; HA, hyaluronic acid; PCL, polycaprolactone; PLLA/PLGA, poly-L-lactic acid/poly-glycolic acid.

stimulator, the PLLA/PLGA suspension sutures, and the cross-linked HA. Such recommendations are needed because previously published consensuses have been focused on the separate use of the PCL collagen stimulator $^{34}$ or the PLLA/PLGA suspension sutures only, ${ }^{40}$ while combination treatments are commonly used in daily practice and may lead to serious problems if followed inappropriate sequencing or spacing (eg, unfavourable interaction between EBD techniques and the PLLA/PLGA sutures). We believe that our recommendations are reliable as they are designed by a multidisciplinary group of experienced physicians, are based on a formal consensus method, and only propose attitudes supported by a high agreement rate. However, the 


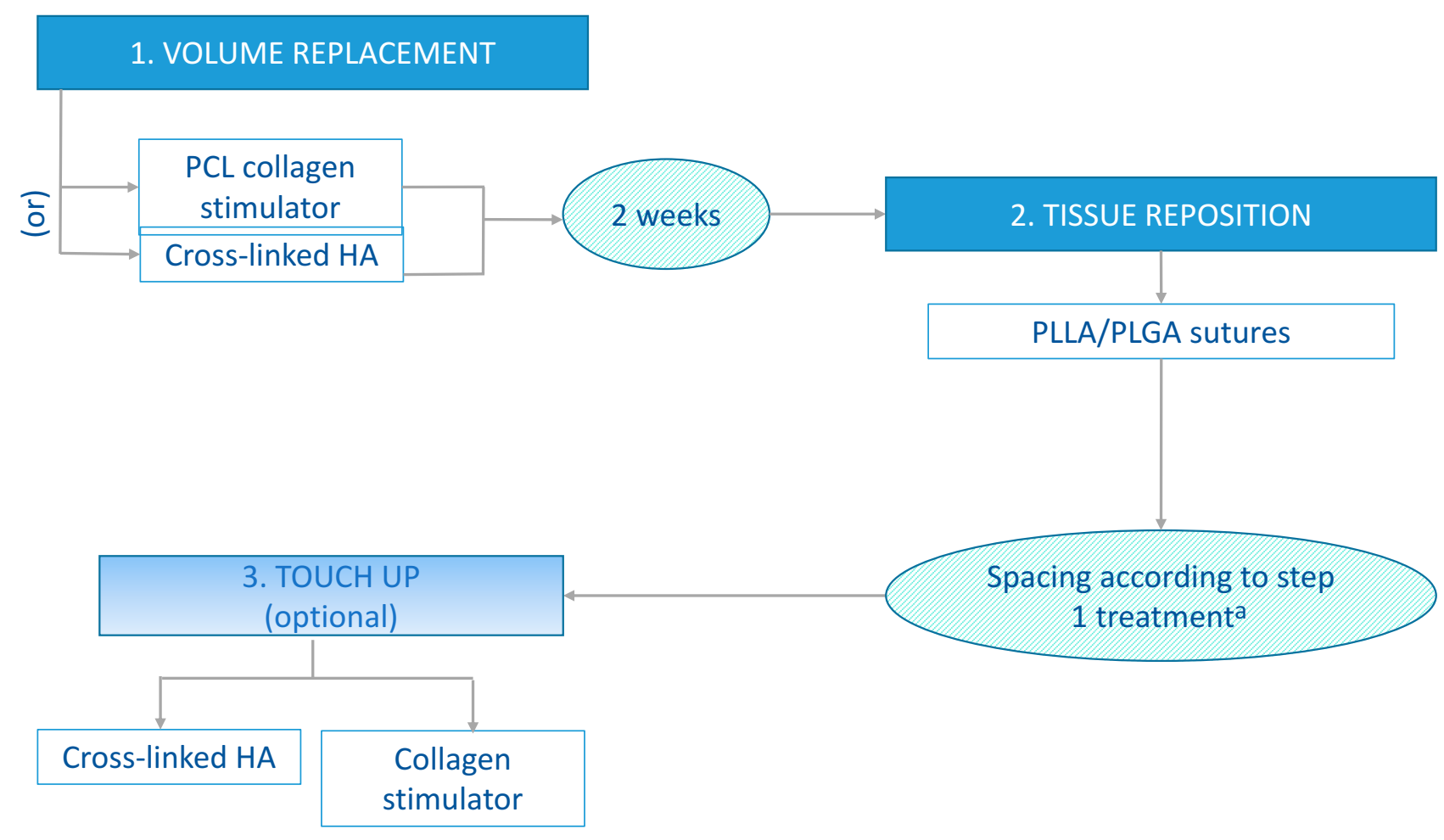

Figure 2 Algorithm for mid-face rejuvenation.

Note: a Spacing between steps 2 and 3: 4-6 weeks if step I treatment was PCL Collagen stimulator or 2 weeks if step I treatment was cross-linked HA. Abbreviations: BoNT, botulinum neurotoxin; HA, hyaluronic acid; PCL, polycaprolactone; PLLA/PLGA, poly-L-lactic acid/poly-glycolic acid.

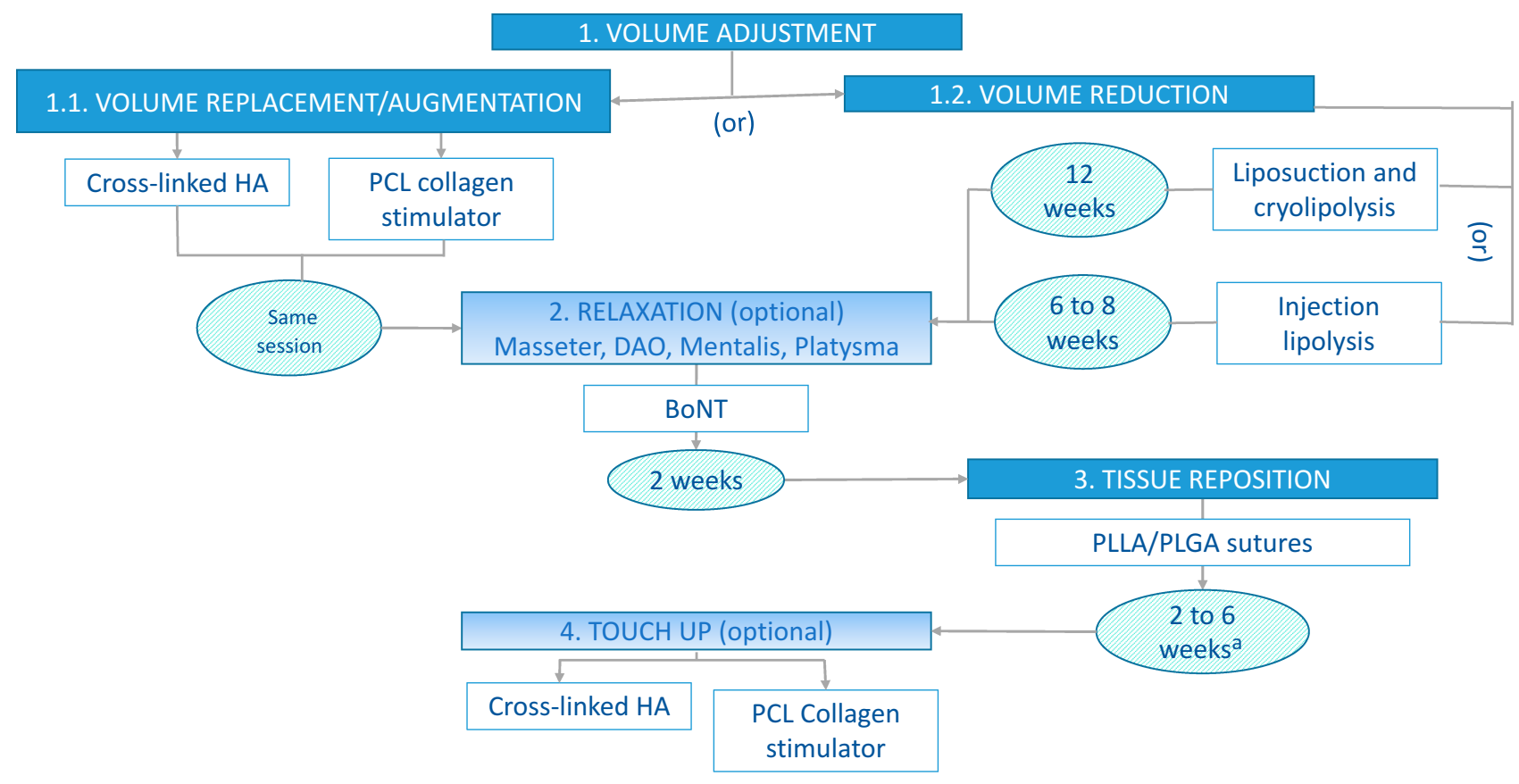

Figure 3 Algorithm for lower-face rejuvenation.

Note: ${ }^{a}$ Spacing between steps 3 and 4: 2 weeks if step I.I is cross-linked HA, or 4 to 6 weeks if step I.I is PCL collagen stimulator.

Abbreviations: BoNT, botulinum neurotoxin; DAO, depressor anguli oris; HA, hyaluronic acid; PCL, polycaprolactone; PLLA/PLGA, poly-L-lactic acid/poly-glycolic acid. 


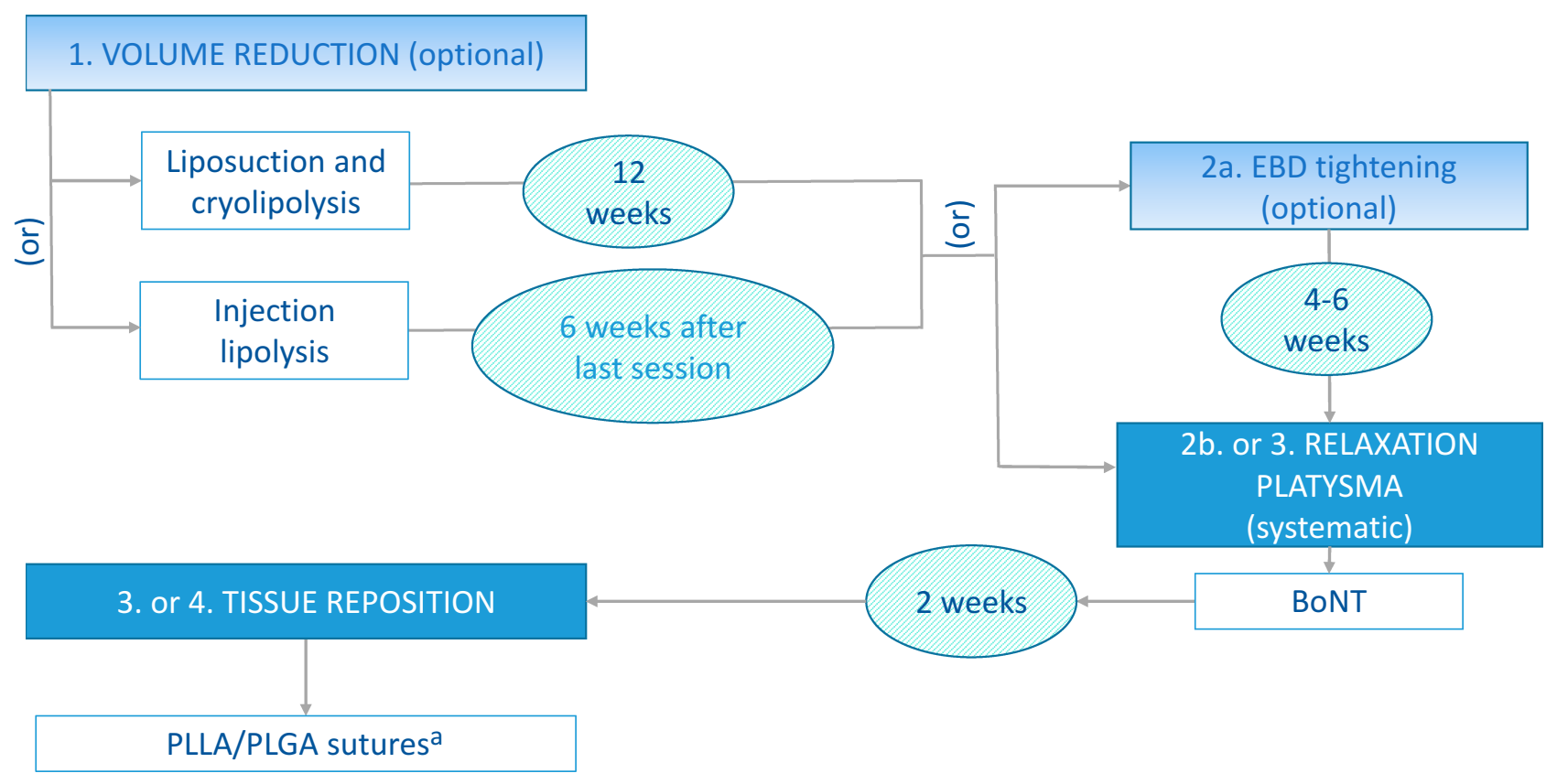

Figure 4 Algorithm for neck rejuvenation.

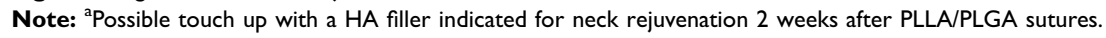

Abbreviations: BoNT, botulinum neurotoxin; EBD, energy-based device; HA, hyaluronic acid; PLLA/PLGA, poly-L-lactic acid/poly-glycolic acid.

US-based board member could not directly comment on the fillers that are not approved by the Food and Drug Administration (FDA) but extrapolated recommendations from the use of FDA-approved fillers. Finally, our recommendations account for a wide range of other commonly used agents and techniques, rendering them probably relevant and helpful in daily practice.

We have deliberately designed our consensus as general guidelines on the best management strategy and not as detailed recommendations on precise problems. This is because the addressed practice field encompasses nearly an infinite number of individual problems. Like all other authors, we acknowledge that such guidelines are never enough - they provide only general support, not an individualized treatment plan. $^{6}$ The optimal treatment plan always results from a physician's individual knowledge (anatomy, aging physiology, product characteristics), training (injection or insertion techniques), general clinical competence, responsibility, and wisdom combined with the patient's values and preferences. ${ }^{17,34}$

Comparable consensus guidelines have also most often specified their recommendation according to separate areas (eg, upper, mid-, and lower face, neck), the type of injected agents or EBDs, and the treatment sequence and timing (Table 4). ${ }^{6,18,51}$ The importance of spacing different treatments (at least one to two weeks) on the same area was generally highlighted to allow the resolution of local side-effects and reliably assess efficacy results and potential AEs. ${ }^{6,51}$ While some injectable agents (BoNTx, HA, CaHA) can safely be used on the same day and in any sequence, EBDs (MFU-V) should be delivered on a separate occasion, preferably before filler injection. $6,18,51$

The main limitations of our guidelines pertain to the drawbacks associated with the expert consensus method and the lack of population specificity. Indeed, it has been emphasized that ethical guidelines should be evidencebased, ie, derived from randomized controlled trials (RCTs) and meta-analyses of RCTs, which bear low risk for bias. ${ }^{1}$ However, RCTs are very rare in the rejuvenation and beautification domain, especially regarding multimodal management. ${ }^{52}$ Thus, as a rule, guidelines on combination treatments have been based on expert consensus, as are ours. ${ }^{6,16,18,51,53,54}$ Compared to these sources, we have used fairly stringent consensus criteria. It has been acknowledged that expert advice may provide valuable guidance for a multi-modal approach to aesthetic treatment. $^{55}$

Parts of the available guidelines are focused on specific subpopulations, according to patients' ethnic origin, gender, or age $\mathrm{e}^{6,18,19,53,54,56}$ as the achievement of optimal outcomes results from a patient-centred treatment plan 
Table 4 Recently Published Consensus Guidelines on Combination Rejuvenation Treatments of the Face and Neck

\begin{tabular}{|c|c|c|c|}
\hline $\begin{array}{l}\text { First Author, } \\
\text { Year }\end{array}$ & Target Areas & $\begin{array}{l}\text { Combination } \\
\text { Treatment } \\
\text { Components }\end{array}$ & Target Population, Consensus Method, Specific Comments \\
\hline Chao $2017^{53}$ & Upper, mid-, and lower face & $\begin{array}{l}\text { BoNTx, CaHA, HA, } \\
\text { MFU-V }\end{array}$ & $\begin{array}{l}\text { Asian patients } \\
\text { Formal consensus-based guidelines } \\
\text { Demand for beautification more common than in Caucasian }\end{array}$ \\
\hline Kapoor $2017^{54}$ & $\begin{array}{l}\text { Upper, mid-, and lower face } \\
\text { Neck }\end{array}$ & BoNTx, HA & $\begin{array}{l}\text { Indian patients } \\
\text { Formal consensus-based guidelines } \\
\text { Facial anthropometry, morphology, and age-related changes in Indians } \\
\text { are specific }\end{array}$ \\
\hline $\begin{array}{l}\text { Carruthers } \\
2016^{6} \\
\text { Fabi } 2016^{51}\end{array}$ & $\begin{array}{l}\text { Upper, mid-, and lower face } \\
\text { Neck, decolletage, hands, upper } \\
\text { arms, abdomen, buttocks, } \\
\text { knees }\end{array}$ & $\begin{array}{l}\text { BoNTx, CaHA, HA, } \\
\text { MFU-V }\end{array}$ & $\begin{array}{l}\text { All Fitzpatrick skin types } \\
\text { Formal consensus-based guidelines } \\
\text { Recommended spacing consecutive treatments on same area I-2 } \\
\text { weeks apart, if possible } \\
\text { MFU-V recommended before injectable agents }\end{array}$ \\
\hline $\begin{array}{l}\text { Sundaram } \\
2016^{18}\end{array}$ & $\begin{array}{l}\text { Upper, mid-, and lower face } \\
\text { Neck }\end{array}$ & $\begin{array}{l}\text { BoNTx, HA } \\
\text { MFUS, RF }\end{array}$ & $\begin{array}{l}\text { Diverse populations, worldwide perspective } \\
\text { Formal consensus-based guidelines } \\
\text { Recommended re-evaluation of patients } 2-4 \text { weeks after either } \\
\text { treatment } \\
\text { Summary statements for specific groups (age, gender, ethnicity) }\end{array}$ \\
\hline $\begin{array}{l}\text { Werschler } \\
2015^{16}\end{array}$ & Face & MFUS, RF $\pm \mathrm{HA}$ & $\begin{array}{l}\text { Caucasians } \\
\text { Informal consensus } \\
\text { Discussion on decision approach (initial assessment; patient } \\
\text { expectations; treatment selection) and various fillers (CaHA, HA, PLLA) }\end{array}$ \\
\hline $\begin{array}{l}\text { Carruthers } \\
2008^{68}\end{array}$ & Upper, mid-, and lower face & BoNTx, HA & $\begin{array}{l}\text { Diverse populations } \\
\text { Informal consensus } \\
\text { Discussion on the influence of patient sex, ethnicity, cultural ideals, } \\
\text { and skin colour; general techniques; patient education and counselling }\end{array}$ \\
\hline Wu $2016^{69}$ & $\begin{array}{l}\text { Upper, mid-, and lower face, } \\
\text { neck }\end{array}$ & BoNTx, HA $\pm I P L$ & $\begin{array}{l}\text { Asian patients } \\
\text { Informal consensus } \\
\text { Treatment selection according to age }\end{array}$ \\
\hline
\end{tabular}

Abbreviations: BoNTx, botulinum neurotoxin; CaHA, calcium hydroxyapatite; HA, hyaluronic acid; IPL, intense pulsed light; MFUS, micro-focused ultrasound; MFU-V, micro-focused ultrasound with visualization; PLLA, poly-L-lactic acid; RF, radiofrequency; wks, weeks.

that accounts for facial morphotype as well as personal and cultural aesthetic ideals. ${ }^{18,19}$ Indeed, facial morphology and age-related changes differ across ethnic groups, ${ }^{54}$ which result in distinct treatment goals and priorities or components of combination treatments. ${ }^{6,18}$ However, the loss of volume occurs in all ethnicities, explaining the reason for volumisation always being a crucial step in rejuvenation treatment. ${ }^{19}$ The qualitative and quantitative differences in treatment are limited for early intervention/ enhancement and restoration, most combination strategies being similar or slightly different in Asian and Caucasian patients. ${ }^{53}$ In addition, our board-convened members from diverse geographic areas and cultural background ideals, and the proposed protocols account for the main variations of ethnic aesthetic problems and ideals. However, our guidelines always need adaptation to specific contexts and individual needs.

\section{Conclusion}

These new practice guidelines will probably prove helpful for practitioners by advising the optimal management strategy in the multimodal rejuvenation treatment of different face areas when combining the PCL collagen stimulator, the PLLA/PLGA suspension sutures, and the cross-linked HA, whether associated or not with other frequently used MIPs. Individual treatment plans should 
always be adapted according to the physician's individual competence and the patient's preferences and needs.

\section{Disclosure}

Dr Francisco de Melo reports personal fees, non-financial support from Sinclair Pharma. Dr Alieksiéi Carrijo, Dr Kyungkook Hong, and Dr Bruno Trumbic report personal fees from Sinclair Pharma. Dr Franco Vercesi was the International Trainer and Key Opinion Leader for Sinclair Pharma. Dr Heidi A Waldorf reports being a honorarium advisory board member for Sinclair Pharma and reports personal fees from Allergan, Endo, Galderma, Merz, Revance, Sinclair Pharma, and Suneva. Dr Sabine Zenker reports personal fees from L'Oréal Paris, Merz, Mesoestetic, Quantificare, and Sinclair Pharma. The authors report no other conflicts of interest in this work.

\section{References}

1. Goh C. The need for evidence-based aesthetic dermatology practice. $J$ Cutan Aesthet Surg. 2009;2(2):65-71. doi:10.4103/0974-2077.58518

2. Carruthers J, Carruthers A. A multimodal approach to rejuvenation of the lower face. Dermatol Surg. 2016;42(Suppl 2):S89-S93. doi:10.1097/DSS.0000000000000749

3. American Society of Plastic Surgeons. 2018 national plastic surgery statistics. 2019. Available from: https://www.plasticsurgery.org/docu ments/News/Statistics/2018/plastic-surgery-statistics-report-2018.pdf. Accessed December 10, 2019.

4. Matarasso A, Nikfarjam J, Abramowitz L. Incorporating minimally invasive procedures into an aesthetic surgery practice. Clin Plast Surg. 2016;43(3):449-457. doi:10.1016/j.cps.2016.03.001

5. Consiglio F, Pizzamiglio R, Parodi PC, et al. Suture with resorbable cones: histology and physico-mechanical features. Aesthet Surg J. 2016;36(3):NP122-NP127. doi:10.1093/asj/sjv202

6. Carruthers J, Burgess C, Day D, et al. Consensus recommendations for combined aesthetic interventions in the face using botulinum toxin, fillers, and energy-based devices. Dermatol Surg. 2016;42 (5):586-597. doi:10.1097/DSS.0000000000000754

7. Johl SS, Burgett RA. Dermal filler agents: a practical review. Curr Opin Ophthalmol. 2006;17(5):471-479. doi:10.1097/01.icu.000024 3021.20499.4b

8. Eppley BL, Dadvand B. Injectable soft-tissue fillers: clinical overview. Plast Reconstr Surg. 2006;118(4):98e-106e. doi:10.1097/01. prs.0000232436.91409.30

9. Yutskovskaya Y, Kogan E, Leshunov E. A randomized, split-face, histomorphologic study comparing a volumetric calcium hydroxylapatite and a hyaluronic acid-based dermal filler. J Drugs Dermatol. 2014;13(9):1047-1052.

10. Goldberg D, Guana A, Volk A, Daro-Kaftan E. Single-arm study for the characterization of human tissue response to injectable poly-L-lactic acid. Dermatol Surg. 2013;39(6):915-922. doi:10.1111/dsu.12164

11. Nicolau P, Marijnissen-Hofsté J. Neocollagenesis after injection of a polycaprolactone based dermal filler in a rabbit. Eur J Aesth Med Dermatol. 2013;3(1):19-26.

12. Ko EJ, Hong JY, Kwon T-R, et al. Efficacy and safety of non-invasive body tightening with high-intensity focused ultrasound (HIFU). Skin Res Technol. 2017;23(4):558-562. doi:10.1111/srt.12371

13. Azuelos A, SidAhmed-Mezi M, La Padula S, Aboud C, Meningaud JP, Hersant B. High-intensity focused ultrasound: a satisfactory noninvasive procedure for neck rejuvenation. Aesthet Surg J. 2019;39(8): NP343-NP351.
14. Ganceviciene R, Liakou AI, Theodoridis A, Makrantonaki E, Zouboulis CC. Skin anti-aging strategies. Dermatoendocrinol. 2012;4(3):308-319. doi:10.4161/derm.22804

15. Alster TS, Garg S. Treatment of facial rhytides with a high-energy pulsed carbon dioxide laser. Plast Reconstr Surg. 1996;98(5):791794. doi:10.1097/00006534-199610000-00005

16. Werschler WP, Calkin JM, Laub DA, Mauricio T, Narurkar VA, Rich P. Aesthetic dermatologic treatments: consensus from the experts. $J$ Clin Aesthet Dermatol. 2015;8(10 Suppl):S2-S7.

17. Fabi S, Pavicic T, Braz A, Green JB, Seo K, van Loghem JA. Combined aesthetic interventions for prevention of facial ageing, and restoration and beautification of face and body. Clin Cosmet Investig Dermatol. 2017;10:423-429. doi:10.2147/CCID.S144282

18. Sundaram H, Liew S, Signorini M, et al. Global aesthetics consensus: hyaluronic acid fillers and botulinum toxin type A-recommendations for combined treatment and optimizing outcomes in diverse patient populations. Plast Reconstr Surg. 2016;137(5):1410-1423. doi:10.10 97/PRS.0000000000002119

19. Palermo EC, Anzai A, Jacomo AL. Three-dimensional approach of cosmetic patient: aging gracefully. In: Issa M, Tamura B, editors. Botulinum Toxins, Fillers and Related Substances. Clinical Approaches and Procedures in Cosmetic Dermatology. Springer; 2019:1-22.

20. Lorenc ZP, Daro-Kaftan E. Optimizing facial rejuvenation outcomes by combining poly-L-lactic acid, hyaluronic acid, calcium hydroxylapatite, and neurotoxins: two case studies. J Drugs Dermatol. 2014;13(2):191-195.

21. Alam M, Kakar R, Nodzenski M, et al. Multicenter prospective cohort study of the incidence of adverse events associated with cosmetic dermatologic procedures: lasers, energy devices, and injectable neurotoxins and fillers. JAMA Dermatol. 2015;151(3):271-277. doi:10.1001/jamadermatol.2014.2494

22. Langelier N, Beleznay K, Woodward J. Rejuvenation of the upper face and periocular region: combining neuromodulator, facial filler, laser, light, and energy-based therapies for optimal results. Dermatol Surg. 2016;42(Suppl 2):S77-S82. doi:10.1097/DSS.0000000000000740

23. Kim JA, Van Abel D. Neocollagenesis in human tissue injected with a polycaprolactone-based dermal filler. J Cosmet Laser Ther. 2015;17 (2):99-101. doi:10.3109/14764172.2014.968586

24. Carruthers J, Carruthers A, Humphrey S. Introduction to fillers. Plast Reconstr Surg. 2015;136(5 Suppl):120S-131S. doi:10.1097/PRS.00 00000000001770

25. Gritzalas K. Preliminary results in using a new dermal filler based on poly-caprolactone. Eur J Aesth Med Dermatol. 2011;1(1):22-26.

26. Taylor MS, Daniels AU, Andriano KP, Heller J. Six bioabsorbable polymers: in vitro acute toxicity of accumulated degradation products. $J$ Appl Biomater. 1994;5(2):151-157. doi:10.1002/jab.770050208

27. Ma G, Song C, Sun H, Yang J, Leng X. A biodegradable levonorgestrel-releasing implant made of PCL/F68 compound as tested in rats and dogs. Contraception. 2006;74(2):141-147. doi:10.1016/j. contraception.2006.02.013

28. Sun H, Mei L, Song C, Cui X, Wang P. The in vivo degradation, absorption and excretion of PCL-based implant. Biomaterials. 2006;27(9):1735-1740. doi:10.1016/j.biomaterials.2005.09.019

29. Galadari H, van Abel D, Al Nuami K, Al Faresi F, Galadari I. A randomized, prospective, blinded, split-face, single-center study comparing polycaprolactone to hyaluronic acid for treatment of nasolabial folds. J Cosmet Dermatol. 2015;14(1):27-32. doi:10.1111/jocd.12126

30. Moers-Carpi MM, Sherwood S. Polycaprolactone for the correction of nasolabial folds: a 24-month, prospective, randomized, controlled clinical trial. Dermatol Surg. 2013;39(3 Pt 1):457-463. doi:10.1111/ dsu. 12054

31. Bae B, Lee G, Oh S, Hong K. Safety and long-term efficacy of forehead contouring with a polycaprolactone-based dermal filler. Dermatol Surg. 2016;42(11):1256-1260. doi:10.1097/DSS.000000 0000000913 
32. Figueiredo VM. A five-patient prospective pilot study of a polycaprolactone based dermal filler for hand rejuvenation. J Cosmet Dermatol. 2013;12(1):73-77. doi:10.1111/jocd.12020

33. Lin SL. Polycaprolactone facial volume restoration of a 46-year-old Asian women: a case report. J Cosmet Dermatol. 2018;17(3):328332. doi: 10.1111 /jocd. 12482

34. de Melo F, Nicolau P, Piovano L, et al. Recommendations for volume augmentation and rejuvenation of the face and hands with the new generation polycaprolactone-based collagen stimulator (Ellansé ${ }^{\mathbb{R})}$ Clin Cosmet Investig Dermatol. 2017;10:431-440. doi:10.2147/ CCID.S145195

35. Sinclair Pharma. Ellanse post market survey (July 2012-31 October 2019). 2019. Available from: https://ellanse.com/our-expertise/. Accessed July 23, 2019.

36. de Benito J, Pizzamiglio R, Theodorou D, Arvas L. Facial rejuvenation and improvement of malar projection using sutures with absorbable cones: surgical technique and case series. Aesthetic Plast Surg. 2011;35(2):248-253. doi:10.1007/s00266-010-9570-2

37. Ogilvie MP, Few JW Jr, Tomur SS, et al. Rejuvenating the face: an analysis of 100 absorbable suture suspension patients. Aesthet Surg $J$. 2018;38(6):654-663. doi:10.1093/asj/sjx202

38. Sarigul Guduk S, Karaca N. Safety and complications of absorbable threads made of poly-L-lactic acid and poly lactide/glycolide: experience with 148 consecutive patients. J Cosmet Dermatol. 2018;17 (6):1189-1193. doi:10.1111/jocd.12519

39. Sinclair Pharma. Silhouette soft post market survey (July 2012-31 October 2019). 2019. Available from: https://silhouette-soft.com/phy sician-home/. Accessed July 23, 2019.

40. Nestor MS, Ablon G, Andriessen A, et al. Expert consensus on absorbable advanced suspension technology for facial tissue repositioning and volume enhancement. J Drugs Dermatol. 2017;16 (7):661-666.

41. Sinclair Pharma. Perfectha. When French touch meets beauty. 2017. Available from: https://perfectha.com/wp-content/uploads/sites/3/ 2017/12/170911-PERFECTHA-Physician-brochure-Johanne-brun ette-model-HD-file.pdf. Accessed July 23, 2019.

42. Christen MO Perfectha safety. A cross-linked hyaluronic acid. Safety data report. 2017. Available from: https://sinclairaesthetics.com/wpcontent/uploads/sites/3/2017/12/170919-Perfectha-Safety-reportvers.-B-HD.pdf. Accessed July 23, 2019.

43. Almeida A, Sampaio G. Hyaluronic acid in the rejuvenation of the upper third of the face: review and update- Part 1. Surg Cosmet Dermatol. 2015;8(2):148-153.

44. Talarico S, Hassun KM, Monteiro E, et al. Safety and efficacy evaluation of a new hyaluronic acid based filler in the treatment of nasolabial folds and lips outline. Surg Cosmet Dermatol. 2010;2 (2):83-86.

45. Taylor-Barnes K. Why Perfectha is my preferred dermal filler for facial rejuvenation. J Aesthetic Nurs. 2016;5:22-25. doi:10.12968/ joan.2016.5.Sup5.22

46. de Almeida AR, de Araújo Sampaio GÂ, Queiroz NP. Hyaluronic acid in the rejuvenation of the upper third of the face: review and update. Part 2: temporal and supraorbital regions. Surg Cosmet Dermatol. 2017;9(2):113-121.

47. Koenig B Analysis of IL-8 inducing potential from human effector cells. Evaluation of inflammatory potential of Perfectha product line by measurement of IL-8 release from adherent macrophages. Study Report. MMD. 2016. Available from: https://perfectha.com/wp-con tent/uploads/sites/3/2017/05/BROCHURE_PERFECHTA.pdf. Accessed July 23, 2019.

48. Sinclair Pharma. Perfectha post market survey (July 2012-October 2019). 2019.

49. Levy PM. The 'Nefertiti lift': a new technique for specific re-contouring of the jawline. $J$ Cosmet Laser Ther. 2007;9(4):249-252. doi:10.1080/14764170701545657
50. Gassia V, Beylot C, Bechaux S, Michaud T. Botulinum toxin injection techniques in the lower third and middle of the face, the neck and the decollete: the "Nefertiti lift". Ann Dermatol Venereol. 2009;136(Suppl 4):S111-S118. doi:10.1016/S0151-9638(09)74537-5

51. Fabi SG, Burgess C, Carruthers A, et al. Consensus recommendations for combined aesthetic interventions using botulinum toxin, fillers, and microfocused ultrasound in the neck, decolletage, hands, and other areas of the body. Dermatol Surg. 2016;42(10):1199-1208. doi:10.1097/DSS.0000000000000869

52. Vanaman M, Fabi SG, Cox SE. Neck rejuvenation using a combination approach: our experience and a review of the literature. Dermatol Surg. 2016;42(Suppl 2):S94-S100. doi:10.1097/DSS.0000 000000000699

53. Chao YYY, Chhabra C, Corduff N, et al. Pan-Asian consensus-key recommendations for adapting the world congress of dermatology consensus on combination treatment with injectable fillers, toxins, and ultrasound devices in Asian patients. $J$ Clin Aesthet Dermatol. 2017;10(8):16-27.

54. Kapoor KM, Chatrath V, Anand C, et al. Consensus recommendations for treatment strategies in indians using botulinum toxin and hyaluronic acid fillers. Plast Reconstr Surg Glob Open. 2017;5(12): e1574. doi:10.1097/GOX.0000000000001574

55. Narurkar VA, Cohen JL, Dayan S, et al. A comprehensive approach to multimodal facial aesthetic treatment: injection techniques and treatment characteristics from the HARMONY study. Dermatol Surg. 2016;42(Suppl 2):S177-S191. doi:10.1097/DSS.0000000000 000743

56. Doh EJ, Kim J, Lee DH, Park JY. Neck rejuvenation using a multimodal approach in Asians. J Dermatolog Treat. 2018;29(4):400-404. doi:10.1080/09546634.2017.1395801

57. Choi SY, Lee YH, Kim H, et al. A combination trial of intradermal radiofrequency and hyaluronic acid filler for the treatment of nasolabial fold wrinkles: a pilot study. J Cosmet Laser Ther. 2014;16(1):3742. doi:10.3109/14764172.2013.854636

58. Dubina M, Tung R, Bolotin D, et al. Treatment of forehead/glabellar rhytide complex with combination botulinum toxin a and hyaluronic acid versus botulinum toxin A injection alone: a split-face, raterblinded, randomized control trial. J Cosmet Dermatol. 2013;12 (4):261-266. doi:10.1111/jocd.12059

59. Dayan SH, Ho TT, Bacos JT, Gandhi ND, Kalbag A, Gutierrez-Borst S. A randomized study to assess the efficacy of skin rejuvenation therapy in combination with neurotoxin and full facial filler treatments. J Drugs Dermatol. 2018;17(1):48-54.

60. Carruthers A, Carruthers J, Monheit GD, Davis PG, Tardie G. Multicenter, randomized, parallel-group study of the safety and effectiveness of onabotulinumtoxinA and hyaluronic acid dermal fillers (24-mg/mL smooth, cohesive gel) alone and in combination for lower facial rejuvenation. Dermatol Surg. 2010;36(Suppl 4):2121-2134. doi:10.1111/j.1524-4725.2010.01705.x

61. Ko EJ, Kim H, Park WS, Kim BJ. Correction of midface volume deficiency using hyaluronic acid filler and intradermal radiofrequency. J Cosmet Laser Ther. 2015;17(1):46-48. doi:10.3109/ 14764172.2014.968579

62. Danhof RS, Cohen JL. A combination approach to perioral rejuvenation. J Drugs Dermatol. 2016;15(1):111-112.

63. Jeon H, Kim T, Kim H, Cho SB. Multimodal approach for treating horizontal neck wrinkles using intensity focused ultrasound, cohesive polydensified matrix hyaluronic acid, and incobotulinumtoxina. Dermatol Surg. 2018;44(3):421-431. doi:10.1097/DSS.0000000000 001312

64. Casabona G, Nogueira Teixeira D. Microfocused ultrasound in combination with diluted calcium hydroxylapatite for improving skin laxity and the appearance of lines in the neck and decolletage. $J$ Cosmet Dermatol. 2018;17(1):66-72. doi:10.1111/jocd. 12475 
65. Fabi SG, Goldman MP, Mills DC, et al. Combining microfocused ultrasound with botulinum toxin and temporary and semi-permanent dermal fillers: safety and current use. Dermatol Surg. 2016;42(Suppl 2):S168-S176. doi:10.1097/DSS.0000000000000751

66. Molina B, David M, Jain R, et al. Patient satisfaction and efficacy of full-facial rejuvenation using a combination of botulinum toxin type A and hyaluronic acid filler. Dermatol Surg. 2015;41(Suppl 1):S325S332. doi:10.1097/DSS.0000000000000548

67. Cuerda-Galindo E, Palomar-Gallego MA, Linares-Garciavaldecasas R. Are combined same-day treatments the future for photorejuvenation? Review of the literature on combined treatments with lasers, intense pulsed light, radiofrequency, botulinum toxin, and fillers for rejuvenation. J Cosmet Laser Ther. 2015;17(1):49-54. doi:10.3109/ 14764172.2014 .968578
68. Carruthers JD, Glogau RG, Blitzer A. Advances in facial rejuvenation: botulinum toxin type a, hyaluronic acid dermal fillers, and combination therapies-consensus recommendations. Plast Reconstr Surg. 2008;121(5 Suppl):5S-30S; quiz 31S-36S. doi:10.1097/ PRS.0b013e31816de8d0

69. Wu WT, Liew S, Chan HH, et al. Consensus on current injectable treatment strategies in the Asian face. Aesthetic Plast Surg. 2016;40 (2):202-214. doi:10.1007/s00266-016-0608-y

\section{Publish your work in this journal}

Clinical, Cosmetic and Investigational Dermatology is an international, peer-reviewed, open access, online journal that focuses on the latest clinical and experimental research in all aspects of skin disease and cosmetic interventions. This journal is indexed on CAS.
The manuscript management system is completely online and includes a very quick and fair peer-review system, which is all easy to use. Visit http://www.dovepress.com/testimonials.php to read real quotes from published authors. 